\title{
Capítulos da história social da medicina no Brasil
}

\author{
Chapters in the social history of \\ medicine in Brazil
}

\author{
Carlos Eduardo Calaça \\ Doutor em história social pela Universidade de São Paulo \\ Rua Lemos Cunha, 538/302 A \\ 24230-130 Niterói - RJ - Brasil \\ calaca@urbi.com.br
}

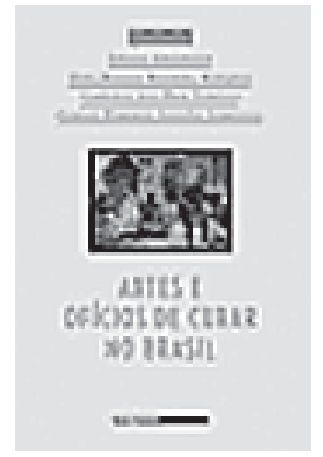

Sidney Chalhoub et al. (org.) Artes e ofícios de curar no Brasil: capítulos de história social.

Campinas (SP):

Ed. Unicamp, 2003. $440 \mathrm{p}$.
A rtes e ofícios de curar no Brasil, organizado por Chalhoub et al., tem o mérito de reunir pesquisadores filiados a diversas instituições de ensino e pesquisa do país e do estrangeiro. Estudiosos radicados em São Paulo, Rio de Janeiro, Paraná, Minas Gerais (São João del Rei), Pará, Rio Grande do Sul, Paraíba, Bahia e nos Estados Unidos (New Haven), ao divulgarem os resultados recentes de suas pesquisas, oferecem ao leitor subsídios adicionais para melhor compreensão do lento processo de institucionalização da medicina nos trópicos e dos conflitos deflagrados pelas autoridades oficiais da cura em face de seus concorrentes, adeptos às concepções terapêuticas 'populares'.

Sem a pretensão de esgotar o tema, os autores elaboraram capítulos da história social da medicina no Brasil, desde o século XVI até o início do XX, interpretando as relações estabelecidas entre intelectuais, médicos, cirurgiões, boticários, sacerdotes, sangradores, pajés, curandeiros, parteiras e diversos setores da população. Ao se debruçarem sobre as trajetórias sociais desses agentes, observam a multiplicidade de saberes e práticas de cura no Brasil, em épocas e contextos diversos. Mesmo que inevitavelmente imbricadas (Xavier in Chalhoub et al., 2003, p. 144; Ribeiro, 1997, p. 89), a defesa intransigente das concepções oficiais deflagrou embates contra seus oponentes.. Não foram poucas as perseguições movidas contra os curandeiros e empíricos, em geral, justificadas, por fatores 'morais', 'religiosos' ou 'científicos' visando extirpar seus conhecimentos e suas práticas. Ora, evidentemente, tais fatores não devem ser descurados, em alguns casos, de interesses políticos e econômicos ou, em motivações carreiristas, individuais, institucionais e classistas.

Cabe aqui uma pausa. $\mathrm{Na}$ introdução redigida pelos organizadores da coletânea, deparamos com algumas questões "que se tornaram cruciais para os autores dos textos da coletânea" (p. 12). Na primeira delas, os organizadores sugerem que desde a segunda metade do século XIX já era visível a relação intrínseca entre "as tentativas de estabelecer o discurso científico como única verdade possível" e o "desenvolvimento da sociedade capitalista ... esforços dos grupos economicamente poderosos do país para manter suas posições de controle e privilégio" (ibidem, p. 12).

Apesar de concordarmos que, em certas circunstâncias, os médicos tenham se empenhado em elaborar estratégias vinculadas aos 
interesses políticos e econômicos, respondendo aos anseios de facções das classes dirigentes, essa abordagem relega para segundo plano a diversidade das motivações individuais, coletivas e profissionais dos médicos, assim como suas estratégias para validar seus conhecimentos. Argumentos semelhantes já foram alvos de inúmeras críticas, seja por atribuírem ao corpo médico o papel de "intelectuais orgânicos" da ordem burguesa, seja por investi-los de um poder que os tornava capazes de intervirem em amplos segmentos da sociedade civil, seja por não atentarem aos seus valores identitários, cognitivos e profissionais, concebendo a classe médica "como télica e homogeneamente devotada à causa disciplinar, com vistas à organização do ethos capitalista" (Carvalho \& Lima, 1992, p. 135; Edler, 1996 e 2002; Coelho, 1999 ).

Voltemos ao que interessa. A longevidade e a difusão de concepções terapêuticas populares, apesar do empenho de sucessivas instituições oficiais em extingui-las, exterminá-las e persegui-las, ao nosso ver, devem ser explicadas em sua legitimidade popular, ora por afinidades culturais e/ou eletivas, ora pela escassez de recursos, ora pela descrença nos procedimentos médico-cirúrgicos oficiais. Em suma, pari passu ao processo de legitimação da medicina acadêmica junto à organização de instituições representativas, a terapêutica popular, ao que parece, engrossou suas fileiras, ao recrutar, além de seus tradicionais adeptos, gente provinda de outras classes sociais, desenganadas e descrentes da eficácia da medicina dos doutores.

A coletânea volta-se para esses e outros temas relacionados às Artes e Ofícios de curar no Brasil. É composta por doze textos de diversos autores, divididos em "Teorias médicas", "Remédios", "Religiosidades" e "Curadores". Trata-se de um trabalho que visa sobretudo suprir lacunas de uma área ainda repleta de interrogações. Sua importância reside, sobretudo, em analisarmos um quadro complexo e amplo das tessituras sociais e dos acirrados conflitos entre os inúmeros agentes da cura na defesa de suas concepções terapêuticas em diversas regiões do Brasil.

No primeiro item, denominado "Ciência e ideologia", Sidney Chalhoub recorre à ironia da obra machadiana para opor a ideologia paternalista à emergência da ciência enquanto viés explicativo para as desigualdades sociais e raciais do final do século XIX. No texto "Para que servem os narizes? Paternalismo, darwinismo social e ciência racial em Machado de Assis", Chalhoub apropria-se da narrativa do personagem protagonista de Memórias póstumas de Brás Cubas, que questiona a função do nariz: teria sido somente criado para uso de óculos? Brás Cubas nega enfaticamente esse pressuposto, tão simplório, e sustenta que "a 'necessidade e poder' do homem de contemplar o seu próprio nariz são modos de obter 'a subordinação do universo a um nariz somente" (p. 19). Segundo Chalhoub, tal conclusão seria uma "metáfora política abrangente". Retrataria uma época em que a classe senhorial deveria olhar para seus próprios narizes "com o fim único de ver a luz celeste" (ibidem, p. 19). Representante, em parte, do modo de vida senhorial, Brás Cubas, ao recordar passagens de sua vida na década de 1840, reproduziria a ideologia paternalista, cujas fronteiras eram 
demarcadas pelo apogeu do poder político e do prestígio social da classe senhorial.

Ocorre que os proprietários sofreram um duro golpe na década de 1870, com a alardeada proximidade da abolição da escravatura. O defunto autor não enxergou com bons olhos aquele estado de coisas, sendo obrigado, no entanto, a se adaptar. Para isso, conta com o auxílio das divagações filosóficas de Quincas Borba, amigo e filósofo que muito lhe tem a ensinar sobre os preceitos da vida. Iniciado no 'humanitismo', Brás Cubas adere, em parte, à filosofia de Quincas Borba, respaldado, segundo Chalhoub, no cientificismo do modelo do darwinismo social, por sustentar idéias tais como as de seleção natural, de sobrevivência do mais apto e outras (p. 44).

Chalhoub, no entanto, ao referir-se a Machado de Assis, chama a atenção do leitor para a postura satírica do autor perante o protagonista de sua história, já que Machado "suspeitava de todo tipo de monismo, ou seja, de qualquer explicação para os fenômenos da natureza e da sociedade baseada nalgum princípio único ou determinação estrita" (ibidem, p. 44). Em suma, provido de inquestionável sensibilidade, Machado de Assis satirizava as permanências, as transformações e os modismos ideológicos de sua geração, centrando suas atenções até mesmo nas ideologias raciais (entre as quais as derivadas da biologia darwinista) que se difundiam nos meios intelectuais da época.

Magali Gouveia Rangel, por sua vez, relata as mazelas de um outro expoente da literatura brasileira. Trata-se de Afonso Henriques de Lima Barreto que acabou protagonista de sua própria história. Sofreu diversos infortúnios durante suas duas passagens pelo Hospital Nacional dos Alienados do Rio de Janeiro, na década de 1920, afrontado por problemas relacionados ao alcoolismo. Seu martírio e resistência são temas do segundo texto do item "Ciência e ideologia", intitulado "A loucura, o hospício e a psiquiatria em Lima Barreto".

Ao abordar a temática do poder, das controvertidas disputas entre as 'verdades científicas', Rangel retrata a estratégia dos alienistas, que reivindicavam para si o domínio sobre a doença mental, e as dificuldades por eles enfrentadas para afirmá-la como um saber especializado (p. 59-60). A conquista, de fato, só iria se concretizar no período republicano, porém, a psiquiatria permaneceu um campo fragilizado, permeável às mais diversas dúvidas e contradições. Rangel revela as vozes dissonantes em relação às 'verdades científicas' difundidas pela psiquiatria e inclui a experiência de Lima Barreto, o qual se permite dialogar com os médicos, questioná-los, suscitar dúvidas no que diz respeito à distribuição dos doentes nas seções, às classificações genéricas emitidas, aos diagnósticos e às curas.

Ao avaliar os sintomas de loucura, Lima Barreto aproximava-se de concepções populares "de que a loucura seria algo imediata e facilmente reconhecível aos olhos de qualquer um", e não apenas aos do especialista, com seus olhares treinados para diagnosticar seus sintomas (p. 68) Adepto, porém, das "luzes do saber", para ele, "aos sábios (verdadeiros), deveria ser concedido o poder (legítimo)" (p. 73). Crítico contumaz do sistema de reclusão asilar, dos procedimentos dos médicos alienistas, Lima Barreto não questionava a razão, o 
conhecimento e o saber como elementos de distinção; não pleiteava combater o saber como elemento constitutivo do poder; pretendia, no entanto, colocar em xeque 'o poder ilegítimo' da psiquiatria de seu tempo.

O texto "Medicina impopular: ciência médica e medicina popular nas páginas dos periódicos científicos", de Luiz Otávio Ferreira, incluído na temática das "Teorias Médicas", nos deixa a par das dificuldades que enfrentaram os esculápios cariocas, durante o século XIX, obrigados a compartilhar seus periódicos com curiosos na tentativa de legitimar seu saber. Ferreira sugere que o processo de 'medicalização' na Corte não ocorreu de forma pacífica.

Os médicos foram obrigados a abrir as páginas de seus periódicos a outras concepções de doença e de cura, sobretudo aquelas originárias dos saberes e das práticas populares e européias (p. 101). O gosto "pelos vomitórios, purgantes, laxantes e outros remédios considerados enérgicos", resultado da persistência "de elementos do humorismo hipocrático na cultura cotidiana", estimulava uma certa moderação nos diagnósticos (p. 112-3).

Apesar do esforço dos médicos em diferenciar a medicina acadêmica de ambos as tradições (a popular e a européia), depararam com a pouca receptividade do público à autoridade cognitiva de seus paradigmas, seja pela descrença, seja pela indiferença às práticas originárias desse saber. Aos médicos, restava a negociação, e, para tanto, viram-se no dilema de utilizar periódicos e dicionários populares como instrumentos de divulgação. Os periódicos, que a princípio deveriam servir como suporte para diferenciar o 'saber científico' dos saberes e práticas concorrentes, tomavam outro rumo: tornaram-se instrumentos fundamentais na popularização da medicina oficial.

Marta de Almeida, no texto "Tempo dos laboratórios, mosquitos e seres invisíveis: as experiências sobre a febre amarela em São Paulo", segundo da série "Teorias Médicas", informa-nos que, no início do século XX, os médicos, longe de estabelecerem um consenso, estiveram imersos "em um processo conflituoso de construção dos saberes" (p. 123-4). Contagionistas, infeccionistas e defensores da medicina patológica e fisiológica travaram lutas em torno dos diagnósticos, das causas e da profilaxia da febre amarela.

Algumas experiências foram realizadas com a utilização de seres humanos, no Hospital de Isolamento de São Paulo. O procedimento é visto pela autora como uma das principais estratégias elaboradas pelos médicos "para comprovar a teoria da transmissão da febre amarela pelo mosquito e negar que o contágio da doença ocorresse pelo contato de objetos ou secreções de pessoas infectadas" (p. 130). Apesar dos resultados positivos das pesquisas, os médicos e as autoridades responsáveis foram alvo de duras críticas, principalmente por colocarem em risco vidas humanas.

Para Almeida, o significado dos debates acerca da febre amarela revela o confronto das teses científicas e a fragilidade dos esculápios em sua tentativa de profissionalização: "eram momentos de debates caracterizados pela diversidade de concepções médicas a respeito das causas da profilaxia das doenças" (p. 151), entre os quais a polêmica 
acerca do combate ao temido mal amarílico, a qual inviabilizaria um consenso por parte dos médicos e, por isso mesmo, fragilizaria os seus postulados científicos.

Na terceira parte do livro, "Remédios", Vera Regina Beltrão Marques, no texto "Medicinas secretas: magia e ciência no Brasil setecentista", discorre sobre as razões da persistência dos medicamentos de segredo no decorrer do século XVIII e primeira metade do século XIX. Tais medicamentos fizeram parte do cotidiano de médicos, de curadores e de uma vasta clientela, embora houvesse, em relação àqueles, estratégias para se diferenciarem de seus rivais.

No século XVIII, os formuladores de segredo, a fim de evitar problemas com as autoridades, procuravam oficializar os seus medicamentos. Os médicos credenciados vangloriavam-se, destacando as suas insígnias, e em seus discursos proliferavam acusações contra feiticeiros e embusteiros, incapazes de validar cientificamente seus produtos. Tais conflitos, no entanto, pouco importavam à população, que consumia medicamentos de todas as naturezas.

Na primeira metade do século XIX, os médicos praticamente se ausentaram das páginas dos periódicos de grande circulação, "inserindose no território da 'ciência' médica, do qual os medicamentos de segredo deveriam ser proscritos" e suas fórmulas submetidas às autoridades competentes para serem estudadas (p. 175, 177). Tal tentativa mostrou-se inócua. Esses medicamentos prosseguiram em uso e seus formuladores, ao não descurar as fronteiras entre ciência e magia, iam "ao encontro de crenças muito arraigadas nas quais não havia lugar para as explicações racionais emanadas da nova ordem trazida pelos homens das Luzes" (p. 185). Os medicamentos de segredo ajustavamse, enfim, ao universo mental da população, mantendo em voga "a credulidade das pessoas e a velha prática de curar que se fazia misteriosamente" (p. 186).

Em "Remédios, charlatanices... e curandeirices: práticas de cura no período da gripe espanhola em São Paulo", Liane Maria Bertucci confronta o linguajar estampado nas propagandas dos medicamentos considerados 'oficiais' com aquele utilizado pelos terapeutas populares que, no início do século XX, dividiram as páginas de grandes jornais paulistas, na iminência de que a epidemia de gripe espanhola atingisse a cidade.

Em meio à proliferação de medicamentos 'oficiais' ditos 'científicos' e pouco eficazes na cura da famigerada doença, os terapeutas populares não deixaram de utilizar recursos semelhantes para propagarem os seus serviços. Se, por um lado, ao oferecerem seus dotes, se apropriavam do argumento da 'credibilidade científica' de seus procedimentos de cura, não se abstinham, por outro lado, de anunciar os efeitos de uma suposta cura milagrosa em suas terapêuticas (p. 210-1). Não tardou para as autoridades se engajarem em combatê-los.

Segundo Bertucci, diante das incertezas no prognóstico e diagnóstico da influenza, os médicos proferiram um discurso relativamente cauteloso: na referência aos medicamentos oficiais, evitavam a utilização de termos como 'cura', substituindo-os por 'indicado' ou 'recomendado'. Além disso, instigava-se, entre os fabricantes dos produtos, 
o recurso às revistas especializadas, o que proporcionaria a definição dos espaços de propaganda dos medicamentos oficiais (p. 214-5). Entretanto, os curandeiros proliferavam em torno da cidade de São Paulo. Gente que utilizava "rezas, xaropadas, folhas, cascas de animais, velas, cruzes, água benta" (p. 216) e que, ao mesmo tempo, prometia acabar com doenças incuráveis, entre as quais a gripe espanhola, com fórmulas secretas, atraindo vastos setores da população.

A "Religiosidade" é o tema dos dois textos seguintes: "Entre a cura e a cruz: jesuítas e pajés nas missões do novo mundo", de autoria de Maria Leônia Chaves de Resende, e "Anfiteatro da cura: pajelança e medicina na Amazônia no limiar do século XX", de Aldrin Moura de Figueiredo. O primeiro reporta-se aos primórdios da colonização européia no Novo Mundo. Trata-se dos desafios enfrentados pelos missionários jesuítas na tentativa de catequização dos povos indígenas. Ao deparar com um grande número de enfermos - doenças primordialmente decorrentes do contato com os europeus -, os padres inacianos se viram na necessidade de redimensionar suas estratégias de conversão, intercalando a catequese (salvação da alma) e a cura (salvação da vida). As atividades de cura para os males do corpo são conseqüência da exigência dos grupos indígenas que não se comportaram como agentes passivos na contenda com os jesuítas e, para tanto, cobravam, entre outras coisas, soluções para as epidemias (p. 212).

Para efetivação de tais processos de resistência, os pajés tornaramse peças fundamentais. Responsáveis pela liderança religiosa dos nativos, eram-lhes atribuídos rituais mágicos associados à cura. Nas missões tornaram-se as principais lideranças no combate aos padres inacianos, que, por sua vez, elaboraram táticas para desacreditá-los perante as populações indígenas: conversão, sedução, humilhação, punição física, exílio ou até mesmo a pena capital (p. 244-55).

Embora obtivessem resultados positivos em tais procedimentos, os jesuítas viram-se forçados a se adaptar a muitas características da pajelança para assegurar a sobrevivência das missões. Segundo Resende, "Aos missionários foram imputadas novas práticas que salvaguardassem a vida da comunidade, prática habitual dos pajés" (p. 255). Se, de fato, famosos pajés se viram desmoralizados, a pajelança persistiu e ganhou novos atores, a saber, os próprios jesuítas. As curas milagrosas, as ameaças do sobrenatural (desta feita, sob a égide de um Deus cristão), eram incluídas nas estratégias de catequização dos nativos.

No segundo artigo que disserta sobre o tema da "Religiosidade", "Anfiteatro da cura: pajelança e medicina na Amazônia no limiar do século XX", Aldrin Moura de Figueiredo mostra a persistência da pajelança em Belém do Pará. Os médicos, já na passagem para o século XX, utilizavam diversos recursos para se inserir no cotidiano da cidade, tendo em vista a respeitabilidade adquirida por seus oponentes. Através dos meios de comunicação, empenharam-se na "constituição da imagem da autoridade médica, do herói da cura e do beneplácito do cidadão" (p. 287) e, principalmente, no poder regenerador da ciência que praticavam.

Por sua vez, os pajés não deixaram de se apropriar do discurso discriminatório, "num sentido inverso ao pronunciado" (p. 282). Os 
jornais, considerados pelo autor como 'mediadores' entre ambas as culturas, engajados em atribuir uma distinção à 'ciência', noticiavam as perseguições policiais, paradoxalmente, à 'ciência dos pajés'. Com isso, à pajelança era atribuída também a conotação de 'ciência'. Os pajés não tardaram a se apropriar desta 'distinção': propagavam suas atividades também como 'científicas' (ibidem, p.282).

A representatividade da 'ciência dos pajés', no caso amazônico sua durabilidade e persistência, em lugar de servir como recurso para endossar a cientificidade da medicina oficial, revelou-a em suas contradições. Os pajés - ao resistirem às perseguições policiais, às acusações de charlatanismo, aglomerando uma vasta clientela de origens sociais diversas, referindo-se às suas curas como 'científicas' - impuseram uma tarefa "extremamente árdua e desgastante para os médicos" na tentativa de legitimar seus ofícios (p. 292). A medicina oficial, no caso de Belém do Pará, para conseguir sua hegemonia científica foi obrigada a enfrentar concorrentes já experimentados há séculos.

A quinta e última parte do livro, intitulada "Curadores", é composta por quatro artigos. O primeiro, de autoria de Tânia Salgado Pimenta, "Terapeutas populares e instituições médicas na primeira metade do século XIX", se detém na resistência das terapêuticas populares diante da tentativa de consolidação das instituições médicas no Rio de Janeiro oitocentista.

Centrando sua atenção na legislação, a autora aborda as relações estabelecidas entre a Fisicatura-Mor e os diversos grupos oficiais ou alternativos entre 1808 e 1850. À época de reinstalação da Fisicatura (entre 1808 e 1828), as autoridades médicas, embora legitimassem muitas práticas de cura alternativas, cristalizavam oficialmente um processo de hierarquização social na distribuição das prebendas. Apesar de receberem os títulos homologados por ela, "sangradores, tiradores de dentes, curandeiros, parteiras, curadores de moléstias específicas eram considerados, segundo a Fisicatura, ofícios inferiores aos de médico, cirurgião e boticários, que tinham prerrogativas sobre o primeiro grupo" (p. 308). Essa estratificação se refletia no prestígio social dos agentes subalternos da arte de curar: eram, em geral, mulheres, escravos, forros ou africanos. Em outras palavras, "a outorga de títulos ... reafirmava o maior ou menor prestígio das pessoas que os recebiam" (p. 308).

A tentativa dos membros da Fisicatura de limitar a ação dos curadores, revelava-se inócua: os terapeutas populares prescreviam remédios e, muitas vezes, atuavam como 'médicos', sem se intimidarem com as restrições legais. A partir de 1828, com o fim da Fisicatura, são lançados na clandestinidade (p. 315). Por sua vez, médicos, cirurgiões, boticários e parteiras passaram a ter na Faculdade de Medicina a garantia da legitimidade de seus saberes e de suas práticas.

O surgimento de instituições médicas e a outorga dos diplomas como insígnias distintivas reordenavam as hierarquias, excluindo os curandeiros populares de exercerem seus ofícios. Apesar da clandestinidade, os curandeiros persistiram nas sendas da cura, assegurados pela existência de uma vasta clientela que diariamente recorria aos seus serviços, seja pela falta de condições de arcar com as despesas 
médicas, seja pelas afinidades culturais no que diz respeito às concepções de doença e de cura (p. 324).

O segundo texto do tópico "Curadores", intitulado "Dos males e suas curas: práticas médicas na Campinas oitocentista", de autoria de Regina Xavier, compara a interação entre pacientes e terapeutas (médicos, homeopatas e curadores), em um período marcado por crises epidêmicas de varíola em Campinas, próspera cidade cafeicultora da província de São Paulo.

No final do século XIX, os defensores da medicina alopática enfrentavam sérias dificuldades: a ambigüidade em diagnosticar e curar servia de trunfo para os seus rivais, os homeopatas e curandeiros, que se multiplicavam angariando uma grossa fileira de pacientes desenganados. Aos médicos, restava lançar mão da legislação, delatando-os como 'charlatães', 'ignorantes' e 'primitivos'. Era parte da luta obstinada dos esculápios em definir o "espaço político e social da medicina alopática, sobretudo quando se pensa na precariedade de seus diagnósticos e métodos curativos" (p. 335). O adensamento do discurso médico, no entanto, se diluía na fluidez da experiência social cotidiana, e a distância entre a terapia oficial e a alternativa "tinha contornos imprecisos" com recorrentes apropriações mútuas entre ambos os saberes (p. 344).

Pouco antes, no ano de 1856, uma outra epidemia, desta feita de cólera, atingira o Nordeste. Em Recife, cem pessoas faleciam diariamente, acometidas pela doença. Os diversos significados atribuídos ao surto e à sua repercussão nas interações entre a população e os diferentes tipos de terapeutas é tema do terceiro texto do item "Curadores", intitulado "As artes de curar nos tempos do cólera: Recife, 1856", de Ariosvaldo da Silva Diniz.

Da mesma forma que alguns anos mais tarde os médicos alopatas seriam postos em xeque nos seus diagnósticos e curas durante a epidemia de varíola, em Campinas, os médicos de Recife se viram às voltas com problemas semelhantes: desconhecia-se a etiologia, o modo de transmissão da doença e um método eficaz para sua cura. Também, em Recife, havia uma forte crença nas medicinas alternativas. A dimensão dessa crença atingiu proporções inusitadas, por exemplo, chegando a provocar motins populares.

Tratava-se, sobretudo, de uma crença arraigada de que os afrodescendentes eram detentores de saberes e práticas específicos para o seu tratamento. Figura protagonista de vários acontecimentos, um curandeiro chamado Pai Manoel imediatamente ganhou fama e, sob protesto dos médicos, foi-lhe reservado, pelas autoridades da província, um espaço no Hospital da Marinha, onde atendia principalmente a 'gente de cor' da cidade. (p. 364). A morte de alguns de seus enfermos foi o suficiente para que os médicos reivindicassem a sua prisão. Mas a população não tardou a protestar, tomando as ruas da cidade. Tratava-se de um motim que guardava como pano de fundo uma interpretação de que a doença era "um sortilégio, um plano diabólico dos brancos para eliminar a gente 'de cor': o cólera seria fruto do envenenamento das comidas e das bebidas, planejado pelos médicos e autoridades governamentais" (p. 371-2). É significativa a alusão de que forjava-se 
uma 'conspiração' contra a 'gente de cor', tendo em vista a iminência de serem substituidos por estrangeiros 'brancos' nas plantações.

De fato, era alta a mortalidade entre negros e mulatos. É certo que esse fator repercutiu também na interpretação das elites que associavam a doença às condições de miséria em que vivia a população. Tais fatores acarretavam outros temores: o de que os escravos domésticos e os de ganho pudessem servir como "veículos que levavam a contaminação para as habitações ricas". Desta visão, constituíam-se os pilares para a intervenção dos higienistas nos mocambos recificenses (p. 371).

O texto de Gabriela dos Reis Sampaio, "Juca Rosa e as relações entre doença e cura no Rio de Janeiro Imperial", último da série "Curandeiros", reforça a importância assumida pelos feiticeiros e curandeiros na capital do Império, no final do século XIX, em especial no caso de Juca, "um dos mais célebres feiticeiros negros que o Rio de Janeiro conheceu" (p. 388). Analisando o processo instaurado contra o legendário feiticeiro, Sampaio desvenda os temores dos grupos dominantes em face da fortíssima presença das práticas culturais de origem africana na capital do Império.

Juca era detentor de uma grande reputação e era procurado por diversos setores da população na busca da resolução de seus problemas cotidianos. No que diz respeito à cura, produzia inúmeros remédios que, combinados com rituais mágicos, eram aplicados nos pacientes (p. 406). Muitas vezes atribuídas ao poder maligno de outros feiticeiros, as doenças do corpo precisavam ser tratadas também através de sortilégios espirituais. Contestando a eficácia do seu método, acusando-o de 'feiticeiro' e 'charlatão', setores do governo imperial, médicos científicos e letrados ocuparam com seus artigos as páginas de jornais, difundindo a idéia de que tais curandeiros, como Juca, representavam o 'barbarismo', o 'atraso', a 'superstição' e 'crendices do vulgo' (p. 414).

Contudo, para a autora, tais discursos tinham como escopo a ideologia da inferioridade racial dos negros, em especial tratando-se de um curandeiro. Rosa, por exemplo, era taxado de "infame crioulo de alma satânica, endurecida pelas superstições africanas" (Cf. Processo José Sebastião da Rosa, 1871, maço 196, gal. C. Arquivo Nacional, RJ, denúncia, apud p. 414). A condenação de Juca Rosa a seis anos de prisão revela, entre outras coisas, o receio das classes dominantes diante da "força com que as práticas culturais negras estavam presentes e difundidas na sociedade" (p. 418). Ameaçado o controle exercido pelas classes senhoriais, posta em xeque a ideologia paternalista, anunciava-se o esfacelamento do sistema escravista: "fazia-se necessária uma repressão mais institucionalizada e rigorosa [o que só ocorreria no período republicano], dada a presença maciça e a força dessas práticas [africanas] no cotidiano de tantas e tão diferentes partes da sociedade" (p. 419). Enquanto isso não ocorria, prendia-se Juca Rosa, acusado de 'feiticeiro' e 'charlatão'.

A coletânea Artes e ofícios de curar no Brasil é, sem dúvida, uma grande contribuição para a história social das concepções terapêuticas, das doenças e das curas nos trópicos. Reflete a importância que tal temática vem adquirindo e amplia o leque de abordagens sobre o tema, revelando documentos de natureza diversa, não descuradas de abordagens 
teóricas e metodológicas, também diversificadas. Traz à tona pesquisas recentes realizadas em diversas regiões, tornando cada vez menos prováveis conclusões precipitadas e unívocas a respeito do tema.

Se nos reportarmos ao período que engloba o século XIX e o início do século XX, por exemplo, período considerado chave para a institucionalização da medicina no Brasil, depararemos com intelectuais, médicos e curandeiros, protagonistas dos mais acirrados embates nos seus diagnósticos e prognósticos e nos significados atribuídos à doença e à cura. Enquanto os médicos alopatas discutiam suas teorias 'científicas', vastos setores da população recorriam às curas alternativas. Desacreditados, os esculápios eram obrigados a negociar as páginas de seus periódicos com leigos e, por vezes, reivindicavam o auxílio das autoridades públicas para prender seus oponentes.

No entanto, inúmeros pajés continuavam atuando em Belém do Pará. 'As gentes de cor' se amotinavam pelas ruas do Recife quando era preso um curandeiro, e as páginas dos jornais cariocas estampavam propagandas de curandeiros detentores de fórmulas secretas, próprias para a cura de qualquer mal, do corpo ou do espírito. Trata-se, em suma, de algumas demonstrações de força de grupos que não serviram tão-somente para endossar a institucionalização da medicina. Encontrados em diferentes épocas e regiões, em geral, rodeados de gente de todas as classes e cor, os curandeiros populares eram também responsáveis por expressões simbólicas ou explícitas de resistência social e cultural em face dos saberes eruditos.

\section{REFERÊNCIAS BIBLIOGRAFICAS}

Carvalho, M. A. R. de; Lima, Nísia Verônica T. 1992

Coelho, Edmundo

Campos 1999

Edler, Flávio Coelho 2002

Edler, Flávio Coelho 1996

Ribeiro, Márcia Moisés 1997
O Argumento Histórico nas Análises de Saúde Coletiva. In: Fleury, Sonia (org.) Saúde Coletiva? Questionando a Onipotência do Social. Rio de Janeiro: Relume-Dumará.

As profissões imperiais: medicina, engenharia e advocacia no Rio de Janeiro: 1822-1930. Rio de Janeiro: Record.

A Escola Tropicalista Baiana: um mito de origem na Medicina Tropical no Brasil. História, Ciências, Saúde-Manguinhos, v. 9, n. 2, p. 357-85, maio-ago.

O debate em torno da Medicina Experimental no Segundo Reinado. História, Ciências, Saúde-Manguinhos, v. 3, n. 2, p. 284-99, jul-out.

A ciência dos trópicos: a arte médica no Brasil do século XVIII. São Paulo: Hucitec. 150 p. 